\title{
A five year histopathological study of granulomatous lesions at a tertiary care centre
}

\author{
Atul Shrivastava ${ }^{1}$, Alpesh M. Maru ${ }^{2, *}$, Tejas S. Choksi ${ }^{3}$, A. S. Agnihotri ${ }^{4}$ \\ ${ }^{1}$ Associate Professor, ${ }^{2}$ Assistant Professor, ${ }^{3}$ Professor, ${ }^{4}$ Professor \& HOD, Dept. of Pathology, ${ }^{1}$ GMERS Medical College, \\ Himmatnagar, Gujarat, ${ }^{2}$ GMERS Medical College, Junagadh, Gujarat, ${ }^{3,4}$ C. U. Shah Medical College, Surendranagar, Gujarat, \\ India
}

*Corresponding Author:

Email: drmaru28@gmail.com

\begin{abstract}
Introduction: Granulomas are common findings in biopsy of various organs. Granulomas are a characteristically focal circumscribed collection of histiocytes along with lymphocytes and giant cells.

Objectives: Present study was undertaken to note the frequency and etiology of granulomatous inflammation in various organs by means of histopathology examination.

Materials and Methods: The prospective study was conducted for five years (January 2011- December 2015) in pathology department of a medical college hospital. The study includes total 510 biopsies which were showing granulomatous origin.

Results: Out of 510 total biopsies, largest number 430 biopsies diagnosed as tubercular inflammation (84.31\%), followed by leprosy $(5.09 \%)$, fungal origin $(2.74 \%)$, parasitic (1.32\%) and cases of granuloma of unknown etiology $(1.78 \%)$.

Conclusion: Most of the granuloma are of infective origin and tubercular granuloma is most common type of etiology in biopsies which shows granulomatous inflammation and lymphnode is the most common affected site.
\end{abstract}

Key words: Granulomatous inflammation, Tuberculosis, Histopathological examination, ZN staining.

\section{Introduction}

On microscopic examination of biopsies, granuloma is most common histopathological finding. Granulomas are focal collection of Epitheloid cells with admixture of multinucleated giant cells and inflammatory cells. ${ }^{1,2}$ The pathogenesis of granulomatous inflammation is considered as a response to pathogens and persistent irritants of exogenous and endogenous origin. ${ }^{3,4}$

Granuloma formation is actually the result of series of events that involves the interplay of persistent antigen (whether endogenous or exogenous) resulting in activation of delayed type of hypersensitivity reaction (type IV), activation of macrophages and $\mathrm{T}$ and $\mathrm{B}$ cell responses with release of chemical mediators of inflammation mainly of cytokines..$^{5-7}$

The Granulomatous inflammation could be classified on the basis of etiology into: bacterial, fungal, viral/chlamydial, helminthic, foreign body type and unknown cause. ${ }^{8}$ And on the basis of the morphology granulomas can be classified as: epithelioid, histiocytic, foreign body, necrobiotic/palisading and mixed inflammatory type. It is necessary to find out the exact etiology of the granulomatous inflammation to start the appropriate treatment so correlating the clinical history with the microscopic findings of histopathological examination proves to be valuable in establishing the correct diagnosis in majority of the cases. ${ }^{9,10}$

The present study was undertaken objective of to find out the frequency, morphology and etiology where ever possible, of granulomatous inflammation in a medical college hospital, and to compare with the similar studies.

\section{Materials and Methods}

The present study was undertaken from January 2011 to December 2015 in the histopathology laboratory of Department of Pathology, C. U. Shah Medical College, Surendranagar.

We have received biopsy samples from all body organs. Specimens were processed as routine and sections were stained with Haematoxyline \& Eosine. Special stains like Ziehl-Neelsen stain, Fite Faraco stain and Immuno Fluorescent stain(AR) were done whenever required.

\section{Observation and Results}

510 cases were diagnosed as Granulomatous lesions, Out of which maximum 430(84\%) cases were of tubercular origin and in granuloma cases other than $\mathrm{TB}$, mostly are of infective origin; in them leprosy was the commonest lesion that is 26 cases followed by Fungal granulomas 24 cases, foreign body granulomas 14 cases, parasitic granulomas 7 cases and 9 cases of unknown etiology (Table 1). Male female ratio was 1.4:1 250(58.33\%) were male patients and $180(41.66 \%)$ were females. out of 430 cases $250(58.33 \%$ ) were male patients and $180(41.66 \%)$ were females, so $1.4: 1$ is the gender ratio in this study.

Age group wise cases of tubercular granuloma shows that maximum number of cases, $186 / 430$ (43.34\%), were reported in the age group of 21-30 years (Table 2). According to the site of distribution, the majority of cases of tuberculosis were reported in the lymph nodes $230(53.34 \%)$ cases followed by G.I.T. $57(13.34 \%)$ cases, Female Genital Tract $43(10 \%)$ 
cases \& Bones and soft tissues accounted for total of $14(3.34 \%)$ cases. (Table 3)

Among 230 involved lymph node, cervical lymph node was most commonly involved followed by Axillary Lymph nodes \& Inguinal Lymph nodes (Fig. 1). Fig. 2 showing Microscopic Pictures of Tuberculosis lesions in various organs, Fig. 2A section from Lymph node biopsy shows many granulomas and amorphous, finely granular, eosinophilic area of central caseous necrosis in granulomas. Fig. 2B section from TB Intestine showing, ulcerated Intestinal mucosa, with submucosa are infiltrated by focal collection of Epithelioid cells and langhans type of giant cells are present in lamina propria with chronic inflammatory infiltrate.

In all 230 cases of lymph nodes we had put $\mathrm{ZN}$ stain, which shows $20.86 \%$ (48 cases out of 230) positivity. Out of these 230 cases 46 cases were randomly selected for Auramine Rhodamine staining which shows that Out of these, 36 cases which were negative for the $\mathrm{ZN}$ stain, were positive for Auramine Rhodamine and 6 cases which were negative for the $\mathrm{ZN}$ stain, were negative for Auramine and Rhodamine also and 4 cases which were positive for the $\mathrm{ZN}$ stain, were also positive for Auramine Rhodamine. [Table 4](Fig. 3A \& 3B)

Common complaints of patients of tuberculosis on biopsy are evening rise of fever, weight loss, and loss of appetite irrespective of organ involvement. All patients (230 cases) of TB Lymphadenitis presented with matted lymph nodes with fever, weight loss and patients diagnosed with TB of Gastro intestinal tracts (57 cases) were presented Pain in abdomen.

Table 1: Incidence of various types of granulomatous diseases in present study (510 cases)

\begin{tabular}{|l|c|c|}
\hline Type of Granulomatous Diseases & Cases & Percentage \\
\hline Tuberculosis & 430 & 84 \\
\hline Leprosy & 26 & 05 \\
\hline Foreign Body & 24 & 05 \\
\hline Fungal Granuloma & 14 & 03 \\
\hline Parasitic Granuloma & 07 & 01 \\
\hline Granuloma of Unknown Etiology & 09 & 02 \\
\hline Total & 510 & 100 \\
\hline
\end{tabular}

Table 2: Showing distribution of Tubercular Granulomas according to the age group

\begin{tabular}{|l|c|c|}
\hline Age groups(Years) & No. of cases & Percentage \\
\hline$<10$ & 00 & $00 \%$ \\
\hline $11-20$ & 28 & $6.67 \%$ \\
\hline $21-30$ & 186 & $43.34 \%$ \\
\hline $31-40$ & 59 & $13.33 \%$ \\
\hline $41-50$ & 36 & $08.33 \%$ \\
\hline $51-60$ & 86 & $20 \%$ \\
\hline$>60$ & 35 & $08.33 \%$ \\
\hline
\end{tabular}

Table 3: Incidence of Tuberculosis in various organs in the present study ( 230 cases)

\begin{tabular}{|l|c|}
\hline \multicolumn{1}{|c|}{ Organ } & No. of cases \\
\hline Lymphnode & $230(53.34 \%)$ \\
\hline G.I.T. & $57(13.34 \%)$ \\
\hline F.G.T. & $43(10 \%)$ \\
Ovary & $33(7.67 \%)$ \\
Fallopian tube & $10(2.33 \%)$ \\
\hline Skin & $21(4.88 \%)$ \\
\hline M.G.T. & $22(5.12 \%)$ \\
Testis & $15(3.46 \%)$ \\
Prostate & $05(1.10 \%)$ \\
Epididymis & $02(0.16 \%)$ \\
\hline Lung & $15(3.34 \%)$ \\
\hline Breast & $14(3.34 \%)$ \\
\hline Buccal Mucosa & $07(1.67 \%)$ \\
\hline Bone & $07(1.67 \%)$ \\
\hline Soft tissue & $07(1.67 \%)$ \\
\hline
\end{tabular}

\begin{tabular}{|l|c|}
\hline Synovium & $07(1.67 \%)$ \\
\hline Total & 430 \\
\hline
\end{tabular}

Table 4: Results of $\mathrm{ZN}$ and AR Staining.

\begin{tabular}{|l|c|c|c|}
\hline \multicolumn{1}{|c|}{ Z.N. Stain } & AR +ve & AR-ve & Total \\
\hline Positive & 04 & 00 & 04 \\
\hline Negative & 36 & 06 & 32 \\
\hline Total & 40 & 06 & 46 \\
\hline
\end{tabular}




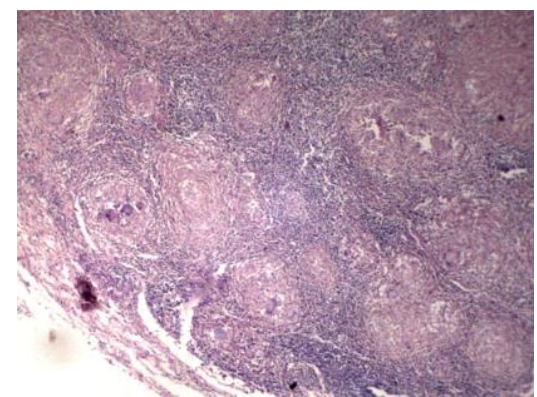

Fig. 2A: Showing morphology of TB Lymph node(H\&E X 100)

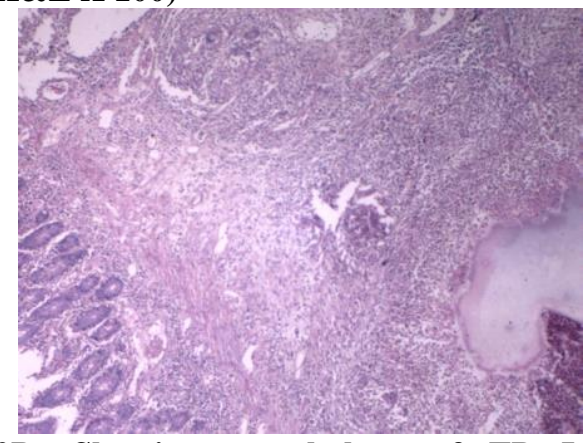

Fig. 2B: Showing morphology of TB Intestine (H\&EX100)

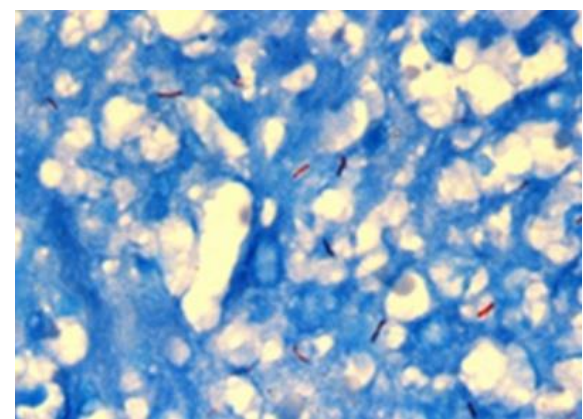

Fig. 3A: Presence of pink colored tubercle bacilli. (ZN X 400)

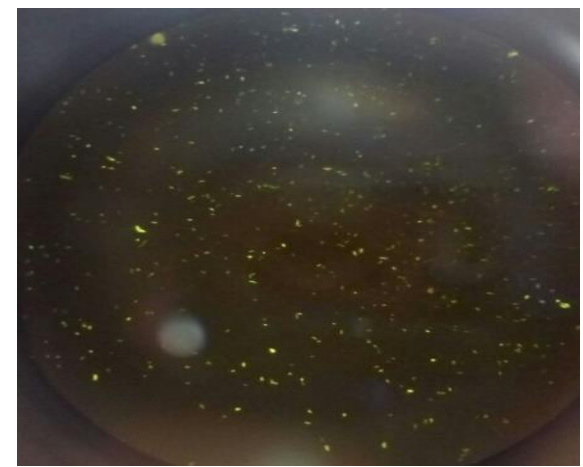

Fig. 3B: Fluorescent staining Slide Positive for AFB (+3) (AR x 400)

\section{Discussion}

Granulomatous inflammation is a specific pattern of chronic inflammation that is encountered in certain number of infectious and non-infectious conditions. In our study, granulomatous lesions were seen predominantly in $3^{\text {rd }}$ decade and in males. The commonest site was lymph node followed by skin and subcutaneous tissues,

Majority of granulomas reported among the males as compared to the females with maximum number of cases in the age group of 21-30 years. These results were similar to the studies done by Permi HS et al, ${ }^{6}$ Pawale JS, ${ }^{8}$ Gulia SP, ${ }^{10}$ Adhikari RC et al, ${ }^{11}$ and Patel et al. ${ }^{12}$

In the present study the majority of the Tuberculosis cases were reported in lymph nodes $(230$ cases, 53.34\%), Adhikari et $\mathrm{al}^{11}$ were also observed similar findings and reported lymph nodes $(41.1 \%)$ as the commonest site of granulomas followed by skin and subcutaneous tissue $(22.0 \%)$, bones and joints (11.5\%), respiratory system $(7.7 \%)$ and gastrointestinal tract $(5.5 \%)$.

As shown in Fig. 1, among lymph nodes cases, majority of granuloma that is 131 cases $(56.92 \%)$ was found in cervical lymph nodes. Similar finding has also been observed by Annam et $\mathrm{al}^{13}$ (72\% cervical Lymphnodes involvement), Thakur et $\mathrm{al}^{14}$ found that among involved lymphnodes, cervical lymphnode affected in $83.3 \%$ cases.

As additional finding of our study from table 4, we found that Flouroscent staining by Auramine rhodamine stain improves the detection of TB bacilli in comparison of conventional ZN stain. Similar Findings also observed by Dagar et $\mathrm{al}^{15}$ and Krishnaswamy et $\mathrm{al}^{16}$ in their studies.

\section{Conclusion}

The most common cause of granulomatous lesion in our study was tuberculosis followed by leprosy and fungal infections. Lymph nodes are the most common site for tubercular granuloma, and among Lymph Nodes, cervical lymph nodes are being the most common site. Most common presenting complains of TB patients are low grade fever, weight loss and loss of appetite.

Funding: No funding sources.

Conflict of interest: None declared.

\section{References}

1. Weedon D. The granulomatous reaction pattern. In: Weedon D(ed). Skin Pathology, $2^{\text {nd }} e d$. Philadelphia: Churchill Livingstone;2002:193-220.

2. Williams G T and Williams W J, Granulomatous inflammation - a review. J Clin Pathol 1983; 36:723-33.

3. Wang WC, Chen JY, Chen YK, Lin LM. Tuberculosis of the head and neck: a review of 20 cases. Oral Surg Oral Med Oral Pathol Oral Radiol Endo 2009;107:381-86.

4. Mariano M. Does macrophage deactivating factor play a role in the maintainence and fate of infectious granulomata? Mem. Inst. Oswaldo Cruz 1991;86:485-87.

5. Vinay Kumar, Abul K. Abbas, Jon C. Aster. Granulomatous inflammation. In: Robbins S. Cottran, eds. 9th ed. The Pathological Basis of Disease. Philadelphia: Saunders; 2014:70-6. 
6. Harish S. Permi, Jayaprakash Shetty K, Shetty K Padma, Teerthanath S, Michelle Mathias, Sunil Kumar Y, Kishan Prasad HL,Chandrika. A Histopathological Study of Granulomatous Inflammation. NUJHS 2012;2(1):15-9.

7. Hirsh BC, Johnson W C. Concepts of granulomatous inflammation. Int J Dermatol 1984;24(2):90-100.

8. Jayashree Pawale, RekhaPurani, MH Kulkarni. A Histopathological study of Granulomatous Inflammations with an attempt to find the Aetiology. JCDR 2011;5(2):301-6.

9. Blessing K. Mini-Symposium: Inflammatory skin Pathology: cutaneous granulomatous inflammation. Current Diagnostic Pathol 2005; 11: 219-235.

10. Gulia SP, Lavanya M, Archana V, ArunKumar SP Histomorphological Analysis Of Granulomatous Lesions In A Teaching Hospital, Puducherry. Int J Cur Res Rev 2015;7(9):78-84.

11. Adhikari RC, Shrestha KB, Savami G. Granulomatous inflammation: A histopathological study. J Pathol Nepal 2013;3:464-68

12. Vaidehi Patel, Jasmin Jasani, RajolI. Desai. The histopathological study of granulomatous diseases in various organs to find the exact etiology of granulomas. IJBAR 2013;4(7):478-83.

13. Annam V, Kulkarni MH, Puranik RB. Comparison of the modified fluorescent method and conventional ZiehlNeelsen method in the detection of acid fast bacilli in lymphnode aspirates. J Cytol 2009;6:13

14. Thakur B, Mehrotra R, Nigam JS. Correlation of various techniques in diagnosis of tuberculous lymphadenitis on fine needle aspiration cytology. Pathol Res Int 2013:824620

15. Dagar et al, Comparision of ZN Staining and Fluorescent Microscopy in Detection of Acid Fast Bacilli in Fine Needle Aspiration Smears IOSR JDMS 2016;15:79-84.

16. Krishnaswamy H, Job CK. The role of Ziehl Neelsen and Flourescent stains in tissue sections in the diagnosis of tuberculosis. Indian J Tuberculosis 1974;21(10):18-21.

How to cite this article: Shrivastava A., Maru A., Choksi T., Agnihotri A. A five year histopathological study of granulomatous lesions at a tertiary care centre. J Diagn Pathol Oncol 2018;3(4):253-56. 